\title{
The need for an integrated theoretical framework for researching the influence of group diversity on performance
}

\author{
John Qin, Bernard O’Meara and Steven McEachern \\ School of Business, University of Ballarat, Ballarat, Australia
}

\begin{abstract}
Purpose Investigating diversity presents researchers with a paradox because extremely inconsistent and conflicting findings about the effects of diversity have emerged in this field of study. It has been argued that the theoretical frameworks used have contributed to the paradox. Different and contradictory effects concerning the influence of group diversity can be predicted using these frameworks. The purpose of this paper is to examine the application of the main theoretical frameworks in the context of researching diversity.

Design/methodology/approach The focus of this paper is a critical examination of three theoretical frameworks in the field of diversity research similarity attraction theory, social categorization theory and the information/decision making approach. These are commonly applied in researching diversity. The basic elements of each theory, its applications in diversity research and its strengths and limitations are considered.

Findings The discussion suggests that the paradox in diversity research emerges from a research tradition that views the three frameworks as being best applied separately because each framework predicts different and even contradictory outcomes. These differences are a consequence of distinctive theoretical operations. In addition, the strengths and limitations associated with each theoretical framework suggest that they might be integrated and subsequently applied in specific settings according to their respective strengths and limitations.

Research limitations/implications In order to produce more consistent results in research on diversity, it is suggested that future researchers should not rely solely on a single theoretical framework to predict the effects of diversity. In particular, different theoretical frameworks may work well with certain types of diversity as well as certain levels of analysis.

Originality/value The paper provides a framework for dissecting the diversity paradox and a foundation for designing fresh approaches that might produce findings that are more consistent.

Keywords Social stratification, Social structure, Groups, The information/decision making approach
\end{abstract}

Paper type Research paper

\section{Introduction}

Despite the intensive efforts to measure and predict the effects of group diversity on performance, research has produced extremely inconsistent and mixed results (Jackson et al., 2003; Mannix and Neale, 2005; Milliken and Martins, 1996; Williams and O'Reilly, 1998). For example, Milliken and Martins (1996, p. 402) noted that "diversity appears to be a double-edged sword, increasing the opportunity for creativity as well as the likelihood that group members will be dissatisfied and fail to identify with the group". This state of knowledge presents a diversity paradox, indicating coexisting and conflicting effects of diversity.

In order to advance understanding about diversity, researchers have dissected the nature of the paradox in research about diversity. Many factors contribute to the paradox, including research contexts, conceptualizations of diversity and theoretical frameworks, which are among the most common causes addressed in the literature. For example, some researchers (cf. Webber and Donahue, 2001) suggest that it may be 
inappropriate to use a single theoretical argument to propose that all types of diversity would have a particular effect. More specifically, Williams and O'Reilly (1998) viewed the mixed results in the light of the different or sometimes contradictory predictions in the commonly used frameworks. They proposed a model to integrate these frameworks. However, despite the various concerns, theoretical frameworks are applied separately in diversity research. Therefore, it seems significant to question whether the application of a theoretical framework itself helps explain the diversity paradox.

However, there is no comprehensive analysis of the current theoretical frameworks in the literature concerning the relationship between various frameworks and the diversity paradox. This paper seeks to fill this gap by examining the salient issues. Following a cursory review of the key concepts, a critical review of the frameworks is conducted. This includes an analysis of each framework's basic theoretical operation, application in diversity research and its strengths and limitations. Finally, the paper discusses the applications of the three frameworks according to common themes. It concludes with suggestions for future research.

\section{The key concepts}

For the purpose of this discussion, diversity is seen as the distribution of any attribute that people use to tell themselves that another person is different (Williams and O'Reilly, 1998). Despite infinite attributes, the most commonly researched attributes of diversity are age, gender, race, functional background, education and tenure (Christian et al., 2006). The most important difference among these attributes is that age, gender and race are more visible and relationship-related while functional background, education and tenure are underlying attributes that are more taskrelated (Mannix and Neale, 2005; van Knippenberg et al., 2004). In this discussion, the former is referred as social diversity while the latter is viewed as information diversity.

The second definition concerns the concept of a group. While defining a work group as a set of individuals "who see themselves and who are seen by others as a social entity, and who perform tasks that affect others" (Guzzo and Dickson, 1996, p. 309), it is necessary to distinguish a work group from a psychological group. In a work group, there are formal or implicit social structures as well as a certain level of task interdependence (Brown, 2000). However, a psychological group is a group that exists psychologically for its members due to perceived similarities that are subjectively significant for or accepted by members of the group (Turner, 1985, p. 80). This distinctness is important since the two concepts have been jumbled in the diversity literature. To avoid confusion, a psychological group is tagged as “(P)".

In this paper, performance is defined as "the accomplishment of organizational objectives, group work assignments or individuals' responsibilities and the contributions to individual/group/organizational goals. Having four sub-domains (that is, objective task performance, subjective task performance, objective contextual performance and subjective contextual performance), it is both results of behaviours and behaviours themselves that create the results" (Qin, 2007, p. 27).

\section{The theoretical frameworks}

Researchers have used a number of theoretical frameworks to develop hypotheses in diversity research. Similarity-attraction theory (SAT), social categorization theory

(SCT) and the information/decision-making approach (IDA) are commonly used frameworks. 


\section{Similarity-attraction theory}

It has been argued that the conceptual foundation for almost all the diversity research has been SAT, originally developed by Byrne (1971) to explain the relationship between similarities in attitudes and interpersonal attraction. Put simply, individuals tend to be attracted to those who are more similar to themselves, causing high levels of interpersonal attraction of a dyad having attitudinal and/or demographic similarities.

Theoretical operations. Although SAT predicts high levels of interpersonal attraction, it has been used in two different approaches. The two approaches are distinguished from each other based on the availability of information about people's attitude. When information about people's attitude is available, the first approach of this theory is to postulate that similarity increases interpersonal attraction and that individuals who share similarities in attitudes, values and beliefs (Sacco and Schmitt, 2005) may find the experience of interaction with each other easier, positively reinforcing and more desirable (Riordan, 2000).

In a slightly different way, when information about people's attitude is not available, the second approach proposes that people who have demographic similarities are likely to be more attracted to one another than to people who are demographically dissimilar. Most diversity studies have taken this approach. However, the linkage between similarity and attraction is indirect. Specifically, the second approach suggests that demographic similarity leads to perceptions of attitudinal similarity, which in turn, leads to reinforced interpersonal attraction (Goldberg, 2003, p. 561). Perceptions of attitudinal similarity arising between demographically similar persons are built on logic: because demographically similar people have more common life experiences and influences that are likely to affect attitudes, the attitudes of this group tend to be similar. In turn, this reinforces the interpersonal attraction (Foley et al., 2006). Particularly, with respect to different demographic attributes, similarities in observable attributes such as, age, race and gender are more likely to affect interpersonal attraction (Goldberg, 2005).

Although being used in different ways, SAT is built on the following fundamentals. Initially, it assumes that when interacting with each other, one individual has a strong tendency (in a free choice situation) to select persons who are similar (Williams and O'Reilly, 1998). The principal reason why people are attracted to and prefer to be with similar others is that they anticipate reinforcement of their own values, attitudes and beliefs (Riordan, 2000). This process, therefore, fosters attraction and the use of a common language that causes greater levels of interpersonal communication, amounts of interaction and social recognition (Christian et al., 2006). In the context of respect and the strength of attraction, SAT implies that the level of interpersonal attraction is dependent on perceived similarity of attitudes between two people (Young et al., 2006). Furthermore, SAT assumes that the similarity between people remains constant, suggesting stable interpersonal attraction between a dyad (Chatman and O'Reilly, 2004). Finally, the theory deals with a dyadic relationship (Byrne, 1971). Based on these fundamentals, SAT suggests that we like those who like us.

Explaining effects of group diversity. In explaining the effects of group diversity, the application of SAT is far beyond dyadic relationships and interpersonal attraction, extending to intergroup relationships as well as communication and social integration (Horwitz, 2005). Specifically, researchers such as Bowers et al. (2000) argued that homogeneous groups are more productive than heterogeneous ones. SAT reinforces this argument in the following sequence. Firstly, using social categories as proxies of attitudinal information, people perceive a higher level of similarity with those who are 
demographically similar compared to the dissimilar. Then, demographically similar people are attracted to each other due to the perceived similarities increasing the level of mutual attraction among members in homogeneous groups. In contrast, the level of mutual attraction in heterogeneous groups is low because dissimilarity is likely to reduce the attraction. Consequently, the process of similarity-attraction produces positive effects on homogeneous groups and causes negative effects on heterogeneous ones. Specifically, this theory predicts that perceived similarity across demographic attributes such as gender, race and tenure has a positive effect on communication, integration, evaluations, attitudes and cohesion within groups. In turn, these have a positive impact on group performance (van Knippenberg et al., 2004). In contrast, it has been suggested that members of heterogeneous groups will tend to have less positive attitudes towards and will form fewer social attachments with those whom they perceive to be less like themselves (Harrison et al., 2002).

Strength and limitations. SAT helps explain interaction between people having similar attitudes or in a same social category. It predicts a person's predisposition to be drawn to similar others. Empirically, the similarity-attraction effect has been found across a variety of contexts (Westmaas and Silver, 2006). For example, attraction was high among individuals who shared similar attitudes, values and beliefs (Tsui et al., 2002). However, SAT has limitations because the theory cannot fully explain how people perceive others in terms of similarity, particularly in relation to their multiple social categories. For example, in a dyadic relationship, how does a middle-aged Chinese man perceive a middle-aged American male of Anglo-Saxon descent?

Another limitation of SAT concerns an assumption that interaction is a necessary condition of the similarity-attraction paradigm (Byrne, 1971). Specifically, researchers have suggested that the similarity-attraction paradigm may not account for all the reported demographic effects, especially in settings when actual interaction among the participants is unlikely (Tsui et al., 2002). Indeed, it has been found that people can express preferences for a group even without social interaction (Foley et al., 2006). In addition, SAT assumes erroneously that people in different social categories should all respond in the same way to being similar or different to others (Chatman and O'Reilly, 2004, p. 193). For example, the similarity-attraction mechanism between two people at different ages might be different from between two persons having different education backgrounds.

\section{Social categorization theory}

SCT describes the process by which people sort each other into groups $(\mathrm{P})$ in terms of social categories (Tajfel and Turner, 1986). SCT has close relationships with other theories such as social identity theory (SIT). This deals with aspects of an individual's self-concept based on his or her social categories memberships and SCT, explaining how people define themselves in terms of membership in social categories (Mannix and Neale, 2005). However, SCT is analyzed only in this paper. There are reasons for doing so. Whereas SIT explains the motivations underlying people's social categorization people have a need for a high level of self-esteem and are, therefore, motivated to achieve and maintain a favourable social identity (Riordan, 2000), it cannot explain the process of how diverse people sort each other into groups (P). Similarly, SCT tells how we fill ourselves into social categories but are unable to deal with others. Therefore, SIT and SCT may have difficulties in explaining effects of group diversity. In contrast, built on the theoretical constructions of SIT and SCT, SCT offers the potential of dynamic interaction in diverse groups. 
The operations of SCT. SCT begins with a basic assumption of SIT; that is, people are motivated to view themselves in the most positive light (Tajfel and Turner, 1986). A primary means to promote a positive self-identity is for people to identify with a group of people who are similar to themselves (Goldberg, 2003). While people define themselves in terms of membership in social groups such as race, age, gender and so forth, only the salient social category of their multiple identities induces the social categorization process (Rink and Ellemers, 2007). With respect to the perception of a salient social category (for example, the attribute of gender) that triggers a corresponding categorization, SCT suggests that generally a person's preference to positive social identities induces that person's unconscious tendency to sort others into social categories.

Specifically, people are likely to differentiate themselves from others based on demographic differences, particularly those that are more visible (for example, gender) compared to the underlying differences (for example, education). This occurs because of the relative difficulties people have in accessing attitudinal information about others (Richard et al., 2006). After identifying the salient social category that is used as the basis of categorization, the similar cognitively categorize themselves into the in-group $(\mathrm{P})$. In the meantime, they sort others into the out-group(s) (P) due to dissimilarity (Christian et al., 2006). The process of social categorization is then complete.

An obvious result of social categorization processes is that a group will be further divided into two sub-groups (P) based on the salience of an attribute. According to SCT, the consequences of social categorization process are profound in diverse groups. Once categorization takes place (that is, a group separates into two or more sub-groups $(\mathrm{P})$ ), people tend to think of others not as unique individuals but as examples of a relevant group stereotype (Tajfel and Turner, 1986), resulting in "us and them" distinctions (Mannix and Neale, 2005).

However, SCT does not posit that people remain at the same social distance once categorization happens. It argues that the salience of social category - the conditions under which some specific group membership becomes a proponent in self-perception and acts as the immediate influence on perception and behaviour - is central to explaining categorization behaviours (Tajfel and Turner, 1986). Particularly, SCT suggests that different aspects of a person's self-concept may become salient in response to the distribution of characteristics of others who are present in a situation (Mannix and Neale, 2005). The perception of a salient social category more or less inevitably triggers a corresponding categorization (Tsui et al., 2002). Following that trigger (that is, a particular social category becomes salient), people use the values and attributes associated with that category to evaluate information and shape action. In other words, people may identify with different social category memberships at different times as a function of changes in the social context, resulting in another social categorization process called re-categorization (Harrison et al., 2002).

The concept of re-categorization provides a dynamic explanation about social categorization by suggesting that people's attention to a specific characteristic in a given situation may change over time. For example, demographically different team members may be hesitant to cooperate with one another because they categorize each other as out-group members. However, if the salience of demographic characteristics at the surface level dissipate over time and demographically dissimilar group members begin to re-categorize themselves as fellow in-group members, they may be more inclined to cooperate with one another (Chatman and Spataro, 2005; Chatman and O'Reilly, 2004). In general, people's perception of a salient social category is not fixed with respect to social categorization process according to SCT. 
Explanations of effects of group diversity. After categorization, people strive for selfesteem by developing positive opinions of their own category and negative opinions of other categories. In doing so, people seek to maximize intergroup (P) distinctiveness and minimize differences within the category (Tsui et al., 2002). While treating the ingroup $(\mathrm{P})$ members favourably, people tend to perceive out-group $(\mathrm{P})$ members as being less attractive (Tajfel and Turner, 1986), resulting in cooperation with in-group (P) members and competition with out-group (P) members (Richard et al., 2006). Consequently, people tend to like and trust members of in-group $(\mathrm{P})$ more than members of out-group $(\mathrm{P})$ and tend to favour in-groups over out-groups generally. This develops into a possibly high level of social attraction in homogeneous groups. The social attraction refers to the interpersonal relationship, which is based on the preferential liking for in-group over out-group members. However, the attraction is towards fellow in-groupers and not to unique individuals (Hobman and Bordia, 2006, p. 485). The social attraction process produces higher commitment, group cohesion and less relational conflict in homogeneous groups, which in turn are likely to perform better (van Knippenberg et al., 2004). In contrast, heterogeneous groups can become a fertile breeding ground for misunderstanding and discord because of potential miscommunication associated with individual differences (Swann et al., 2004). Heterogeneous groups, in turn, are predicted to have worse performance compared to homogeneous groups.

Strength and limitations. SCT has received substantial support from the results of empirical research. For example, researchers have demonstrated that people differentiate themselves from others because of observable differences in age, race, gender and the like and some concealed social identities like homosexuality (see Harrison et al., 2002). With respect to the consequences of social categorization, people who regard themselves as members of superior groups experience anxiety concerning interaction with others who they regard as inferior (Mannix and Neale, 2005; Williams and O'Reilly, 1998).

However, while SCT provides a useful explanation for the behaviour of people in responding to difference, its explanations are not comprehensive. For instance, it has been suggested that people in a social context tend to identify with others with whom they share characteristics that are relatively rare in a particular context (Mehra et al., 1998). This tendency suggests that similarity is relative to the context and that the social categorization process is more likely to happen in low diversity groups. Indeed, research demonstrates that the relative rarity of a social category in a particular social context is likely to promote a member's use of that group as a basis for shared identity and social interaction (Mehra et al., 1998).

In addition, whereas SCT suggests that people use social categorization processes to enhance self-esteem, suggesting an active nature of social categorization, there is evidence to suggest that people sometimes identify strongly with groups that are disadvantaged and stigmatized (Swann et al., 2004). This situation suggests that social categorization is not only an active process but also a passive one, implying that people may be unwillingly assigned to social categories (Garcia-Prieto et al., 2003).

Although scholars have used SCT to explain the effects of underlying diversity (for example, Harrison et al., 2002), it was developed originally to explain the effects of readily detected diversity such as race and gender (Chatman and O'Reilly, 2004). That is, the more readily accessible the social category, the more easily that category may be used for social categorization (Tsui et al., 2002). Empirical research in which SCT has been used to predict effects of underlying diversity is, therefore, problematic. 


\section{Information/decision-making approach}

The IDA explains how information and decision-making can be affected by the group diversity. It is the theoretical basis for people arguing for value in diversity.

Operations. The IDA is based on two basic assumptions. The approach assumes that individuals with different demographic characteristics also have very different qualities such as knowledge, skills, abilities, experiences and other characteristics (KSAOs) (Jayne and Dipboye, 2004). That is, social diversity is likely to cause information diversity. In addition, this approach suggests that diverse groups have greater potential to access other individuals with different backgrounds, networks, information, skills and experiences (Christian et al., 2006). Based on these assumptions, the IDA suggests that demographic diversity provides diverse groups with a large pool of KSAOs, offering diverse groups a variety of perspectives and approaches to the problems-in-hand as well as different sources of information and expertise available (van Knippenberg et al., 2004).

Arguably, a large pool of KSAOs contributes to quality decision-making (Jayne and Dipboye, 2004). Simultaneously, groups of members having multiple perspectives are more likely to avoid groupthink in decision-making (Horwitz, 2005). According to this approach, diversity causes information (cognitive) diversity, which in turn influences team decisions and thus performance (Mannix and Neale, 2005). Furthermore, the IDA suggests that the large pool of KSAOs associated with diversity can be developed fully in diverse groups, suggesting a diversity that is manageable (Rijamampianina and Carmichael, 2005).

Explanations of effects of diversity. In an optimistic way, researchers have argued that diverse groups, especially in facing a complex and non-routine decision environments, are more likely to possess a broader range of task-relevant knowledge, skills and abilities. The potential talent gives the diverse group a larger pool of resources resulting in some beneficial effects such as a rational decision-making process, creativity and innovative ideas or solutions (Bachmann, 2006), particularly in the case of highly complex and uncertain tasks. In such environments, it is necessary for groups to pull together their diverse functional expertise and resources in order to formulate strategies to deal with problems (Horwitz, 2005).

Strength and limitations. The IDA has been supported by the findings of empirical research. There is evidence showing that the availability of multiple resources and skills causes members of diverse group to be more innovative and creative in problem solving than members of homogeneous groups (Rink and Ellemers, 2007). In addition, another study has revealed that in solving complex and non-routine problems, diverse groups are more effective (Simons and Pelled, 1999). In another context, Watson et al. (2003) argue that conflicts associated with group heterogeneity may be combined with fast decision-making. However, the IDA has also been criticized for its limitations.

In opposition to one of the assumptions of this approach, it has been argued that diversity is sometimes simply not manageable (Robb and Douglas, 2004). This feature of diversity suggests that problems caused by diversity may outweigh the benefits associated with diversity (Williams and O'Reilly, 1998). Furthermore, demographic diversity does not necessarily produce other types of diversity (for example, information (cognitive) diversity). For example, age does not always reflect values or even work experiences (Jehn et al., 1999). Increasing diversity, therefore, does not necessarily improve the KSAOs (Jayne and Dipboye, 2004; Webber and Donahue, 2001). 


\section{Discussion}

The previous section reviewed the applications of three theoretical frameworks used in the diversity research. A discussion of the findings is presented below according to four themes, which emerged from the review above.

\section{Diversity dimensions}

In general, the three frameworks have been applied to all types of diversity, including both social and information diversity. However, it is suggested that these frameworks have very different orientations towards the dimensions of diversity. With respect to SAT, the similarities in observable attributes (that is, social diversity) like age, race and gender are more likely to affect interpersonal attraction (Goldberg, 2005). With respect to SCT, it was suggested that people are likely to differentiate themselves from others based on visible differences (that is social diversity) (Swann et al., 2004). With respect to the IDA, it focuses on information diversity but assumes that social diversity causes information diversity. There is a lack of theoretical guidance to explain how the types of diversity may operate differently to influence performance. However, there is consensus in the literature that different types of diversity may have different impacts on performance (Mannix and Neale, 2005). Therefore, it is not surprising to see different or even conflicting results in research when one framework has been applied to both types of diversity.

Levels of concerns. In the group context, diversity can be analyzed at the group or individual level. There are two approaches: the first approach (at the individual level) is the relational demography approach that treats diversity as a social relationship between an individual and the group or another group member (as in the case of dyads). The second approach (at the group level) is the compositional or distributional approach that deals with diversity as a collective property of a group (Tsui et al., 2002). The theoretical frameworks have been applied at both levels despite their strengths at a particular level, particularly SAT and SCT. Specifically, SAT was developed to understand dyadic relationships (Byrne, 1971) in contrast with SCT that is built on social attraction, which is based on the preferential liking for in-group over out-group members. However, the attraction towards fellow in-groupers (not unique individuals) is highly dependent on prototypical features of group membership (a collective property) (Hobman and Bordia, 2006, p. 485). Therefore, SCT may not be able to account fully for the effects of diversity concerning personal attraction in dyadic relationships while SAT cannot fully explain the effects of diversity in social attraction.

Predicted effects. With respect to predicted effects, SAT and SCT do not predict direct effects on performance. Instead, the SAT suggests positive effects of perceived similarity in social diversity on communication, integration, evaluations, attitudes and cohesion within groups. In turn, these have a positive impact on group performance (van Knippenberg et al., 2004). In a similar vein, SCT predicts positive effects on commitment, group cohesion and negative effects on relational, which in turn lead to better performance (Hobman and Bordia, 2006). However, using these frameworks, diversity research has directly linked diversity with performance, creating a "black box" between diversity and performance (Lawrence, 1997). Some researchers have even suggested that:

The effects of different forms of demographic diversity to organizational outcomes have been unclear (mixed), mostly because previous studies have not considered a theoretical framework and have not articulated the intervening group processes through which the 
relationship between forms of diversity and important outcomes operate (Bayazit and Mannix, 2003, p. 296).

The need to articulate the intervening group process may also apply to the IDA. Whereas the IDA predicts effects on innovation and creativity (Bachmann, 2006), which are measures of performance, it has been argued that the relationship between diversity and innovation is mediated by group processes such as task conflict (Passos and Caetano, 2005).

Contextual factors. Contextual factors are relevant to the three frameworks. Specifically, SAT implies that the level of interpersonal attraction is dependent on perceived similarity of attitudes between two people (Foley et al., 2006). They suggest that the attraction is influenced by the multiple identities presented. For example, the attraction based on gender is likely to be stronger between two mainstream White American males compared to the attraction between one African American male and one mainstream White American male. Similarly, SCT suggests the temporal factor that causes re-categorization implying that people's attention to a specific characteristic in a given situation may change over time (Chatman and Spataro, 2005). In a different way, the IDA argues that diverse groups, especially when they face complex and non-routine decision environments are more like to benefit from diversity (Rink and Ellemers, 2007). This implies that the nature of a task moderates the effects of diversity. Therefore, without confederations of contextual factors, research results about effects of diversity are likely to vary across situations and circumstances.

\section{Conclusion}

The above discussion suggests that both SAT and SCT highlight the distinctiveness or difference of social identities, while the IDA focuses on KSAOs associated with different individuals. With respect to effects of diversity, SAT and SCT both suggest negative impacts on performance, while the IDA predicts positive impacts on performance. Superficially, the diversity paradox may result from a research tradition that uses these frameworks in research separately, based on different and contradictory predictions. However, this paper moves the debate one further step, showing four themes that are more specific, where the application of frameworks might have actually contributed to the diversity paradox.

Firstly, it may be incorrect to use one of the frameworks to propose that all types of diversity would have a particular effect on group processes and performance. Instead, different types of diversity might have different effects on performance. Secondly, given their strengths in explaining the effects of diversity at a specific level, the frameworks must be applied at different levels accordingly. Moreover, as the frameworks predict indirect effects on performance, it is necessary to articulate the intervening group processes that may account for the relationship between diversity and performance. Finally, as the three frameworks point to the influence of contextual factors, research results about the effects of diversity are likely to vary across situations, especially if the contextual factors have not been considered.

Therefore, the paper concludes with the view that it is unwise to begin to comprehend the dynamics of how diversity influences performance without integrating the three approaches. In this light, an integrative theoretical framework might reduce the paradox effect in diversity research. Moreover, developing an integrative theoretical framework to explain diversity in group settings remains a significant challenge for all researchers in the field. 


\section{References}

Bachmann, A. (2006), "Melting pot or tossed salad? Implications for designing effective multicultural workgroups", Management International Review, Vol. 46, pp. 72147.

Bayazit, M. and Mannix, E. (2003), “Should I stay or should I go?”, Small Group Research, Vol. 34 No. 3, pp. 290321.

Bowers, C., Pharmer, J. and Salas, E. (2000), "When member homogeneity is needed in work teams”, Small Group Research, Vol. 31 No. 3, pp. 30527 (via Business Source Premier, EBSCO).

Brown, R. (2000), Group Processes: Dynamics Within and Between Groups, 2nd ed., Blackwell Publishers, London.

Byrne, D. (1971), The Attraction Paradigm, Academic Press, New York, NY.

Chatman, J. and O’Reilly, C. (2004), "Asymmetric reactions to work group sex diversity among men and women”, Academy of Management Journal, Vol. 47 No. 2, pp. 193208.

Chatman, J.A. and Spataro, S. (2005), "Using self categorization theory to understand relational demography based variations in people's responsiveness to organizational culture", Academy of Management Journal, Vol. 48 No. 2, pp. 32131.

Christian, J., Porter, L. and Moffitt, G. (2006), "Workplace diversity and group relations: An overview”, Group Processes and Intergroup Relations, Vol. 9 No. 4, pp. 45966.

Foley, S., Linnehan, F., Greenhaus, J. and Weer, C. (2006), "The impact of gender similarity, racial similarity, and work culture on family supportive supervision”, Group and Organization Management, Vol. 31 No. 4, pp. 42041.

Garcia Prieto, P., Bellard, E. and Schneider, S. (2003), "Experiencing diversity, conflict, and emotions in teams", Applied Psychology: An International Review, Vol. 52 No. 3, pp. 41340.

Goldberg, C. (2003), "Applicant reactions to the employment interview: A look at demographic similarity and social identity theory", Journal of Business Research, Vol. 56 No. 8, pp. 5612.

Goldberg, C. (2005), "Relational demography and similarity attraction in interview assessments and subsequent offer decisions", Group and Organization Management, Vol. 30 No. 6, pp. 597624.

Guzzo, R. and Dickson, M. (1996), "Teams in organizations recent research on performance and effectiveness", Annual Review of Psychology, Vol. 47, pp. 30738.

Harrison, D., Price, K., Gavin, J. and Florey, A. (2002), "Time, teams, and task performance: changing effects of surface and deep level diversity on group functioning", Academy of Management Journal, Vol. 45 No. 5, pp. 102945.

Hobman, E. and Bordia, P. (2006), "The role of team identification in the dissimilarity conflict relationship", Group Processes and Intergroup Relations, Vol. 9 No. 4, pp. 483507.

Horwitz, S. (2005), "The compositional impact of team diversity on performance: theoretical considerations", Human Resource Development Review, Vol. 4 No. 2, pp. 21945.

Jackson, S., Joshi, A. and Erhardt, N. (2003), "Recent research on team and organizational diversity: SWOT analysis and implications”, Journal of Management, Vol. 29 No. 6, p. 801.

Jayne, M. and Dipboye, R. (2004), "Leveraging diversity to improve business performance: research findings and recommendations for organizations", Human Resource Management, Vol. 43 No. 4, pp. 40924.

Jehn, K., Northcraft, G. and Neale, M. (1999), "Why differences make a difference: A field study of diversity, conflict, and performance in workgroups", Administrative Science Quarterly, Vol. 44 No. 4, pp. 74163.

Lawrence, B. (1997), "The black box of organizational demography", Organization Science: A Journal of the Institute of Management Sciences, Vol. 8 No. 1, pp. 122 (via Business Source Premier, EBSCO). 
Mannix, E. and Neale, M. (2005), "What differences make a difference?", Psychological Science in the Public Interest, Vol. 6 No. 2, pp. 3155.

Mehra, A., Kilduff, M. and Brass, D. (1998), "At the margins: A distinctiveness approach to the social identity and social networks of underrepresented groups", Academy of Management Journal, Vol. 41 No. 4, pp. 44152.

Milliken, F. and Martins, L. (1996), "Searching for common threads: understanding the multiple effects of diversity in organizational groups", Academy of Management Review, Vol. 21 No. 2, pp. 40224.

Passos, A. and Caetano, A. (2005), "Exploring the effects of intragroup conflict and past performance feedback on team effectiveness", Journal of Managerial Psychology, Vol. 20 Nos. 3 4, pp. 23144.

Qin, J. (2007), "Distinguishing Negative and Positive effects of diversity: A solution to resolve the diversity paradox", working paper, School of Business, University of Ballarat, Ballarat.

Richard, O., Ford, D. and Ismail, K. (2006), "Exploring the performance effects of visible attribute diversity: the moderating role of span of control and organizational life cycle", International Journal of Human Resource Management, Vol. 17 No. 1, pp. 2091109.

Rijamampianina, R. and Carmichael, T. (2005), "A Pragmatic and holistic approach to managing diversity", Problems and Perspectives in Management, No. 1, pp. 10917.

Rink, F. and Ellemers, N. (2007), "Diversity as a basis for shared organizational identity: the norm congruity principle”, British Journal of Management, Vol. 18 No. 1, pp. 1727.

Riordan, C. (2000), "Relational demography within groups: past developments, contradictions, and new directions", in Ferris, G. (Ed.), Research in Personnel and Human Resources Management, JAI Press, Greenwich, CT.

Robb, M. and Douglas, J. (2004), "Managing diversity", Nursing Management UK, Vol. 11 No. 1, pp. 259.

Sacco, J.M. and Schmitt, N. (2005), "A dynamic multilevel model of demographic diversity and misfit effects", Journal of Applied Psychology, Vol. 90 No. 2, pp. 20331.

Simons, T. and Pelled, L. (1999), "Making use of difference: diversity, debate, and decision comprehensiveness in top management teams", Academy of Management Journal, Vol. 42 No. 6, pp. 66273.

Swann, W., Polzer, J., Seyle, D. and Ko, S. (2004), "Finding value in diversity: verification of personal and social self views in diverse groups", Academy of Management Review, Vol. 29 No. 1, pp. 927.

Tajfel, H. and Turner, J. (1986), "The social identity of intergroup behavior", in Worchel, S. and Austin, W. (Eds), Psychology and Intergroup Relations, Nelson Hall, Chicago, IL, pp. 724.

Tsui, A., Porter, L. and Egan, T. (2002), "When both similarities and dissimilarities matter: extending the concept of relational demography”, Human Relations, Vol. 55 No. 8, pp. 899929.

Turner, J. (1985), "Social categorization and the self concept: A social cognitive theory of group behavior", in Lawler, E. (Ed.), Advances in Group Processes: Theory and Research, JAI Press, Greenwich, CT, pp. 77121.

van Knippenberg, D., de Dreu, C. and Homan, A. (2004), "Work group diversity and group performance: An integrative model and research agenda", Journal of Applied Psychology, Vol. 89 No. 6, pp. 100822.

Watson, W., Stewart, W. and BarNir, A. (2003), "The effects of human capital, organizational demography, and interpersonal processes on venture partner perceptions of firm profit and growth", Journal of Business Venturing, Vol. 18 No. 2, pp. 14564.

Webber, S. and Donahue, L. (2001), "Impact of highly and less job related diversity on work group cohesion and performance: A meta analysis", Journal of Management, Vol. 27 No. 2, pp. 14162. 
Westmaas, J. and Silver, R. (2006), "The role of perceived similarity in supportive responses to victims of negative life events", Personality and Social Psychology Bulletin, Vol. 32 No. 11, pp. 153746.

Williams, K. and O'Reilly, C. (1998), "Demography and diversity in organizations, a review of 40 years of research", in Staw, B. and Sutton, R. (Eds), Research in Organizational Behavior, Vol. 20, JAI Press, Greenwich, CT, pp. 77140.

Young, A., Cady, S. and Foxon, M. (2006), "Demystifying gender differences in mentoring: theoretical perspectives and challenges for future research on gender and mentoring", Human Resource Development Review, Vol. 5 No. 2, pp. 14875.

\section{About the authors}

John Qin, after graduating in 1994, worked with the Howly Group, a medium size company in China, as a Senior Manager. After eight years of service, he attended the University of Durham (UK) in 2002, where he gained his MBA and postgraduate diploma in research methods. Currently, as a $\mathrm{PhD}$ candidate, he is investigating the effects of diversity from the perspective of the diversity conflict performance relationship. John Qin is the corresponding author and can be contacted at: j.qin@ballarat.edu.au; qingui123@hotmail.com

Bernard O'Meara has worked extensively in industry in general management corporate based human resource roles in the manufacturing sector. He has been Principal Director of a Melbourne based consulting group and specializes in human resource management and strategic management. Bernard has lectured at Deakin University and the University of Ballarat in Australia for the last six years. He has contributed to a text on industrial relations, presented at numerous conferences and written joint articles. Currently, he is supervising several research students.

Steven McEachern is the author of a number of journal papers, has received an Australian Research Council Grant and over $\$ 500,000$ in other research income. Steven currently supervises four $\mathrm{PhD}$ students and has successful Honours completions. Steven's area of expertise is survey methodologies. 